\title{
Specific pattern of gene expression during induction of mouse erythroleukemia cells
}

\author{
Peter J. Fraser and Peter J. Curtis \\ The Wistar Institute of Anatomy and Biology, Philadelphia, Pennsylvania 19104 USA
}

\begin{abstract}
We have studied the expression of several characterized genes during induction of mouse erythroleukemia (MEL) cells with dimethyl sulfoxide (DMSO) and have observed a specific pattern of changes in transcriptional activity and steady-state RNA levels associated with erythroid differentiation. During induction there is a gradual, steady decrease in total transcriptional activity and RNA content per cell, which by day 3 of DMSO treatment amounts to less than $50 \%$ of the level in the uninduced cell. During this time we observe increases in transcriptional activity for 5-aminolevulinic acid synthase, carbonic anhydrase form II, and band 3 coordinate with the large increase in $\beta$-globin gene transcription. The results also demonstrate an early decrease in transcription for carbonic anhydrase form I, which precedes decreases in transcription for glyceraldehyde phosphate dehydrogenase and rRNA genes. Changes in steady-state RNA levels reflected changes in transcriptional activity during induction except for carbonic anhydrase II mRNA. These results represent the first report characterizing the regulated expression at transcriptional and posttranscriptional levels of several known genes that are characteristically expressed in the erythrocyte. The results demonstrate that coordinate gene expression in erythroid differentiation occurs primarily at the level of transcription.
\end{abstract}

[Key Words: Coordinated gene regulation; transcriptional activity; erythroid differentiation]

Received June 25, 1987; revised version accepted August 14, 1987.

Adult erythroid differentiation requires activation and/ or modulation of many genes whose expression is regulated both temporally and quantitatively. The result is the generation of highly specialized cells whose functions and capabilities are defined by expression of specific gene products. Several of these genes are considered tissue specific, such as globin and glycophorin /Colin et al. 1986), in that their expression is restricted to cells of erythroid lineage. Others, such as the genes for carbonic anhydrase form I (CAI) (Tashian 1977) and erythroid forms of the anion transport protein, band 3 (Cox et al. 1985), and the cytoskeletal protein spectrin (Riederer et al. 1986), are limited in expression to a few tissues, but may still be considered erythroid specific. A third class of genes exist that are expressed in nearly all tissues but maintain erythroid-specific patterns of inducibility or modulation. Examples of this latter group are 5-aminolevulinic acid (ALA) synthase (Sassa 1976), the first enzyme in the heme biosynthetic pathway, and carbonic anhydrase form II (CAII) (Tashian 1977), which is involved in the reversible hydration of $\mathrm{CO}_{2}$. Both these genes are expressed in a variety of tissues, but their expression is specifically modulated during erythroid differentiation. Several of the gene products induced during erythroid differentiation, for example, the heme biosynthetic enzymes and $\alpha$ - and $\beta$-globin polypeptides, are mutually dependent for function and presumably require coordination of expression. Likewise, peripheral and integral membrane proteins must be expressed coor- dinately such that they may assemble to form the characteristic erythrocyte cytoskeleton.

One approach to the study of gene expression in erythroid differentiation utilizes the mouse erythroleukemia (MEL) cell system. MEL cells are erythroid precursor cells transformed by the Friend virus complex. Upon addition of dimethyl sulfoxide (DMSO) or a variety of other agents, MEL cells undergo a series of biochemical and morphological changes that closely resemble the events of normal erythroid differentiation. Volloch and Housman (1982) have shown that under the proper culture conditions, subcloned, rapidly inducing MEL cells undergo changes in morphological characteristics similar to those of normal mouse orthochromatophilic erythroblasts and reticulocytes, resulting in terminal differentiation and enucleation. Among the observed changes are progressively smaller cells and increasingly condensed nuclei, leading to a reduction in RNA content and a decreased rate of synthesis of total RNA (Sherton and Kabat 1976). The most dramatic and oft noted change is the marked increase in the rate of transcription of $\alpha$ - and $\beta$-globin genes resulting in accumulation of globin mRNA and hemoglobin (Aviv et al. 1976; Curtis and Weissmann 1976; Nudel et al. 1977; Orkin and Swerdlow 1977; Lowenhaupt et al. 1978; Hofer et al. 1982). Also observed is an increase of newly synthesized carbonic anhydrase II mRNA (Curtis 1983) as well as increased synthesis of $\alpha$ - and $\beta$-spectrin (Eisen et al. 1977; Pfeffer et al. 1986), band 3 (Sabban et al. 
1980), band 4 (Pfeffer and Redman 1981), and other erythroid-specific polypeptides. Induction of the activities of the heme synthesizing enzymes ALA synthase, ALA dehydrase, uroporphyrinogen synthase, and ferrochelatase have also been reported (Sassa 1976).

In MEL cells, accumulation of globin mRNA and hemoglobin has been shown to result mainly from an increase in the rate of transcription of the globin gene (Ganguly and Skoultchi 1985). However, little or no information is available concerning the regulation of other genes expressed during erythroid differentiation. Our study attempts to identify regulatory steps in the expression of coordinately controlled genes by examining the expression of several genes involved in the specific pattern of gene activation and inactivation during MEL cell induction. Cloned cDNAs for mouse $\alpha$-spectrin, band 3, CAI, CAII, globin, ALA synthase, and glyceraldehyde phosphate dehydrogenase (GAPD) and genomic sequences for ribosomal RNA were used to determine the changes in transcription rates and steady-state RNA levels of the respective genes. Our results demonstrate changes at the transcriptional level that are accompanied by changes in steady-state levels. ALA synthase, CAII, band 3, and globin show transcriptional increases at approximately the same time, suggesting the possibility of coordinate control of transcription of these genes.

\section{Results}

Changes in transcription rate during $M E L$ cell induction

To assess changes in transcription rate for the various genes during induction, we employed in vitro nuclear run-on techniques. Nuclei were isolated from $10^{8}$ cells from each time point: uninduced cells (day 0 ) and cells treated with $1.8 \%$ DMSO for 1,2 , and 3 days (days $1-3$ ). [ $\left.{ }^{32} \mathrm{P}\right] \mathrm{UTP}$ was incorporated into nascent RNA via elongation and isolated for hybridization to immobilized plasmids containing cDNA inserts. Figure 1 displays the results of ${ }^{32} \mathrm{P}$-labeled nuclear RNA, obtained from MEL cells from days $0-3$, hybridized to plasmids containing cDNA inserts.

To obtain data that would indicate the change in transcription rate of a gene during induction, it is necessary to measure the transcriptional activity of a gene for a constant number of cells, rather than as a proportion of total transcriptional activity, which diminishes with time after induction. The amount of labeled RNA used in the hybridizations was equivalent to that obtained from an equal number of cells from each day. Our results are therefore proportional to the number of RNA molecules produced from a given gene per cell over unit time and indicate the change in the rate of synthesis of RNA at that locus for each day.

Previous studies have shown and our results confirm that induction of MEL cells with DMSO is accompanied by a decrease in transcriptional activity (Orkin and Swerdlow 1977; Patel and Lodish 1984). Transcriptional output, measured in terms of total yield of TCA-precipi-

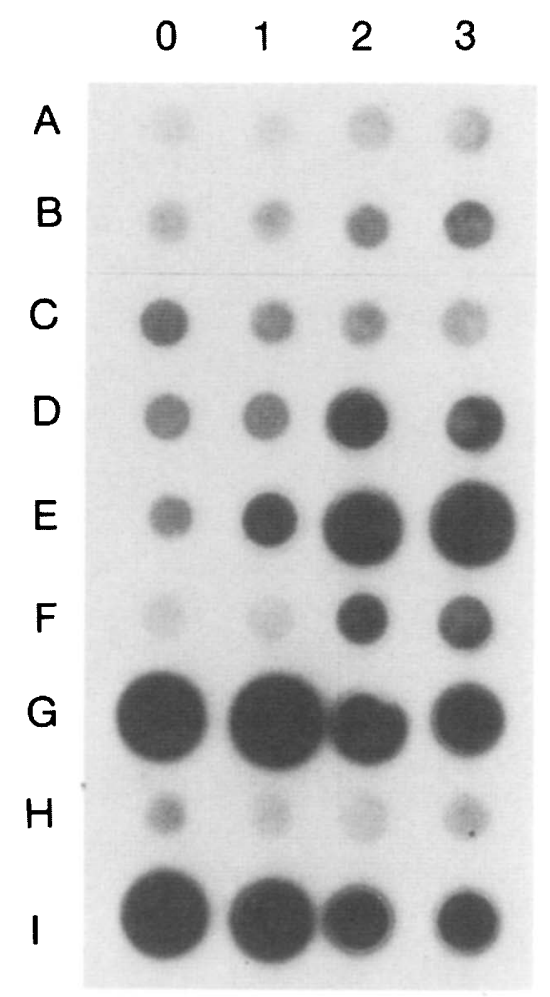

Figure 1. Autoradiogram of in vitro transcription assay with isolated nuclei from MEL cells from days $0-3$ of DMSO treatment. Four separate hybridization vessels were used, each of which contained a set of filters $(\mathrm{A}-\mathrm{H})$ and an equal proportion of the total yield of ${ }^{32} \mathrm{P}$-labeled nuclear RNA from day $0,1,2$, or 3. Filter I (rRNA) was hybridized separately with $1 / 22$ as much [32P]RNA as filters A-H. (A) $\alpha$-Spectrin; (B) band 3; (C) CAI; (D) CAII; (E) globin; (F) ALA synthase; (G) GAPD; $(\mathrm{H})$ rabies virus glycoprotein; (I) rRNA.

table counts, dropped greater than $50 \%$ from day 0 to day 3 (Fig. 2A).

As is characteristic of MEL cell induction, we observe a greater than 40 -fold increase per cell in globin gene transcription. ALA synthase shows a parallel increase in transcription. For both these genes the largest increase occurred on day 2 , with the transcription rate reaching its highest point on day 3 . Increases in transcription are also seen for carbonic anhydrase form II (CAII) and band 3 . CAII also shows its largest increase in transcription on day 2 before decreasing on day 3 .

Transcription of rRNA and GAPD decreased during induction, with the most significant reductions occurring between days 1 and 2 , falling $60 \%$ and $80 \%$, respectively. CAI transcription was highest in the uninduced MEL cell, followed by a rapid decrease of nearly $50 \%$ in the first $24 \mathrm{hr}$ of induction. CAI transcription levels continued to decline to near background levels by day 3 . A graphic representation of the actual number of counts bound after correcting for background is shown in Figure 2. In all our transcription experiments with MEL cells, the signals obtained for $a$-spectrin were not significantly above those of the negative control plasmid $\mathrm{pRG}$, which contained a cDNA for the rabies virus glycoprotein. The 

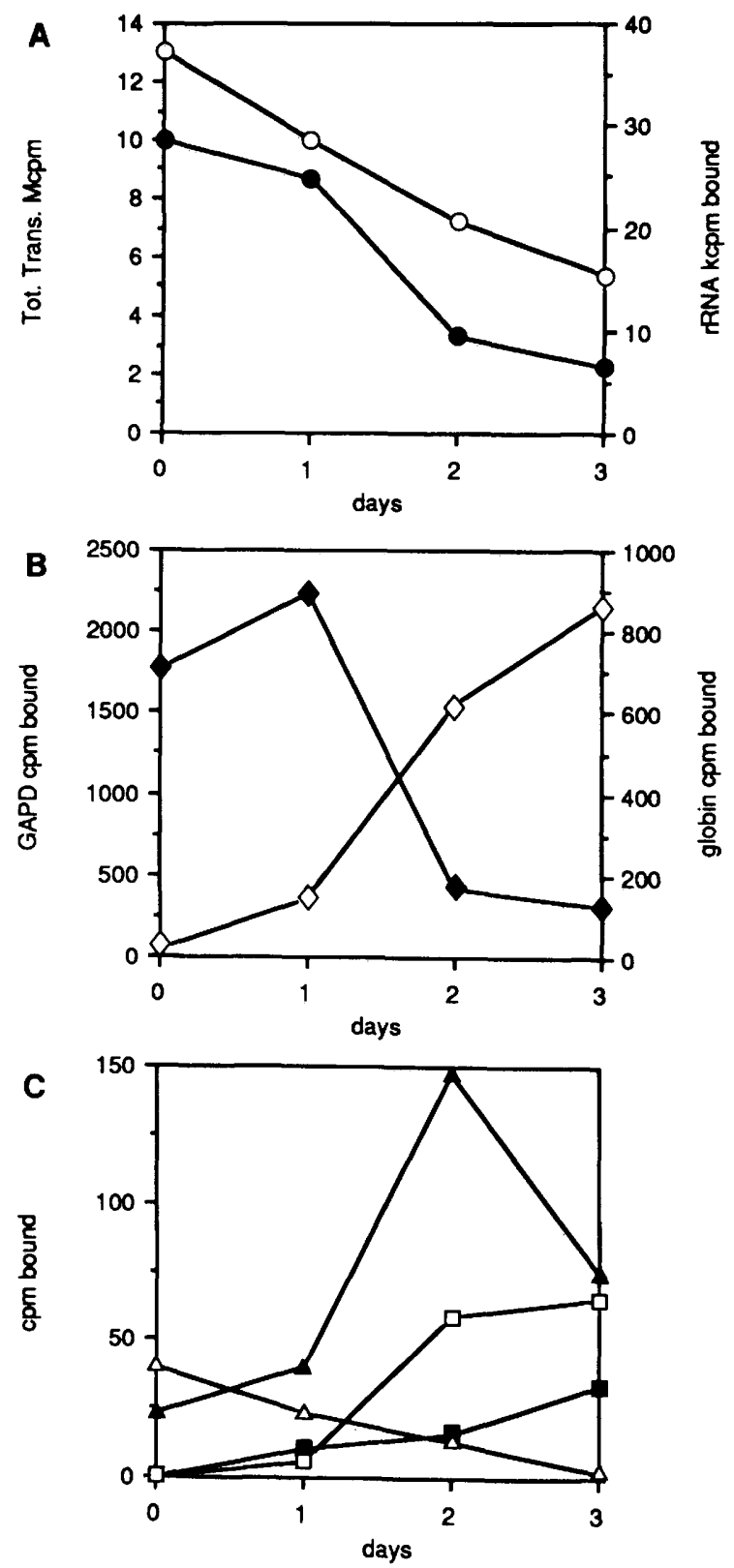

Figure 2. Graphic representation of changes in transcription rate for the various genes, as determined by in vitro transcription assay with isolated nuclei. Each filter from Fig. 1 was counted separately in scintillation fluid before mounting for autoradiography. The values shown above indicate ${ }^{32} \mathrm{P}$ counts per minute bound to each filter after correcting for background hybridization by subtracting the value of the negative control plasmid pRG (rabies glycoprotein) for each day. $(A)(O)$ Total transcription; $(O)$ rRNA. $(B)(\diamond)$ GAPD; $(\diamond)$ globin. $(C)(\Delta)$ CAII; $(\triangle) \mathrm{CAI}_{;}(\square)$ ALA synthase; ( $\left.\square\right)$ band 3.

results obtained for the remaining genes were consistently reproducible.

\section{Changes in steady-state RNA levels during MEL cell induction}

Steady-state RNA levels were assayed during MEL cell induction through analysis of total RNA isolated from MEL cells on days $0-3$. Since MEL cells undergo sharp reductions in cell volume and RNA content during induction, results obtained assaying equal amounts of total RNA for days $0-3$ would indicate the change in the fraction or percentage of total RNA that contained sequences specific for our probes. To obtain results that would indicate the average change in the level of a mRNA on a per-cell basis, we used an equal number of cells from each day and modified our total-RNA preparation procedure to correct for variable recovery by adding an internal standard. Briefly, $10^{8}$ cells were harvested from each time point, and upon lysis in SDS, $2 \times 10^{5}$ cpm of $\left[{ }^{3} \mathrm{H}\right] \mathrm{RNA}$ was added to each sample. Purification of total RNA proceeded as previously described. The yield of total RNA from each day was corrected for variable recovery by quantitation of ${ }^{3} \mathrm{H}$ counts, and the amount of RNA in $10^{8}$ cells was determined. The range of recovery was $65-75 \%$. Our results indicate a $50 \%$ decrease in the average amount of total RNA per cell from day 0 to day 3 .

Total RNA from approximately $7 \times 10^{5}$ cells from each day (i.e., equal amounts of ${ }^{3} \mathrm{H}$ counts) were electrophoresed in formaldehyde-containing agarose gels, transferred to nitrocellulose, and hybridized with ${ }^{32} \mathrm{P}-\mathrm{la}$ beled cDNA probes. A dramatic increase in the steadystate level of globin mRNA, which is characteristic of MEL cell induction, is seen in Figure 3. ALA synthase mRNA levels also increase per cell, in parallel with globin. CAII and GAPD show minor reductions by day 3 of induction, whereas CAI is dramatically reduced from the level in the uninduced cell. Band 3 mRNA was below detectable levels in MEL total RNA but was readily detectable in preparations of mouse anemic spleen total RNA (data not shown). The changes in steady-state levels noted above were consistently observed.

\section{Discussion}

We have determined the changes in transcriptional activity and steady-state RNA levels for a number of characterized genes, in addition to globin, on a per-cellaverage basis using DMSO-inducible MEL cells as an erythropoietic model system. Induction is most notably characterized by a marked increase in globin gene transcription and accumulation of globin mRNA as has been reported by a number of independent investigators (Aviv et al. 1976; Curtis and Weissmann 1976; Nudel et al. 1977; Orkin and Swerdlow 1977; Lowenhaupt et al. 1978; Hofer et al. 1982). Our results show that even though the total transcriptional output of the cell is drastically reduced during induction, globin gene transcription increases greater than 40 -fold. In addition, our findings demonstrate concomitant increases in the transcription rates of CAII, ALA synthase, and band 3 genes with the largest increases occurring on day 2 or 3 . There is an early decrease in transcription for CAI within the first $24 \mathrm{hr}$ of induction, and large decreases in transcription for GAPD and rRNA genes on day 2.

Through analysis of total RNA and comparison with our transcription data we were able to correlate changes in the transcription rates of the various genes with 


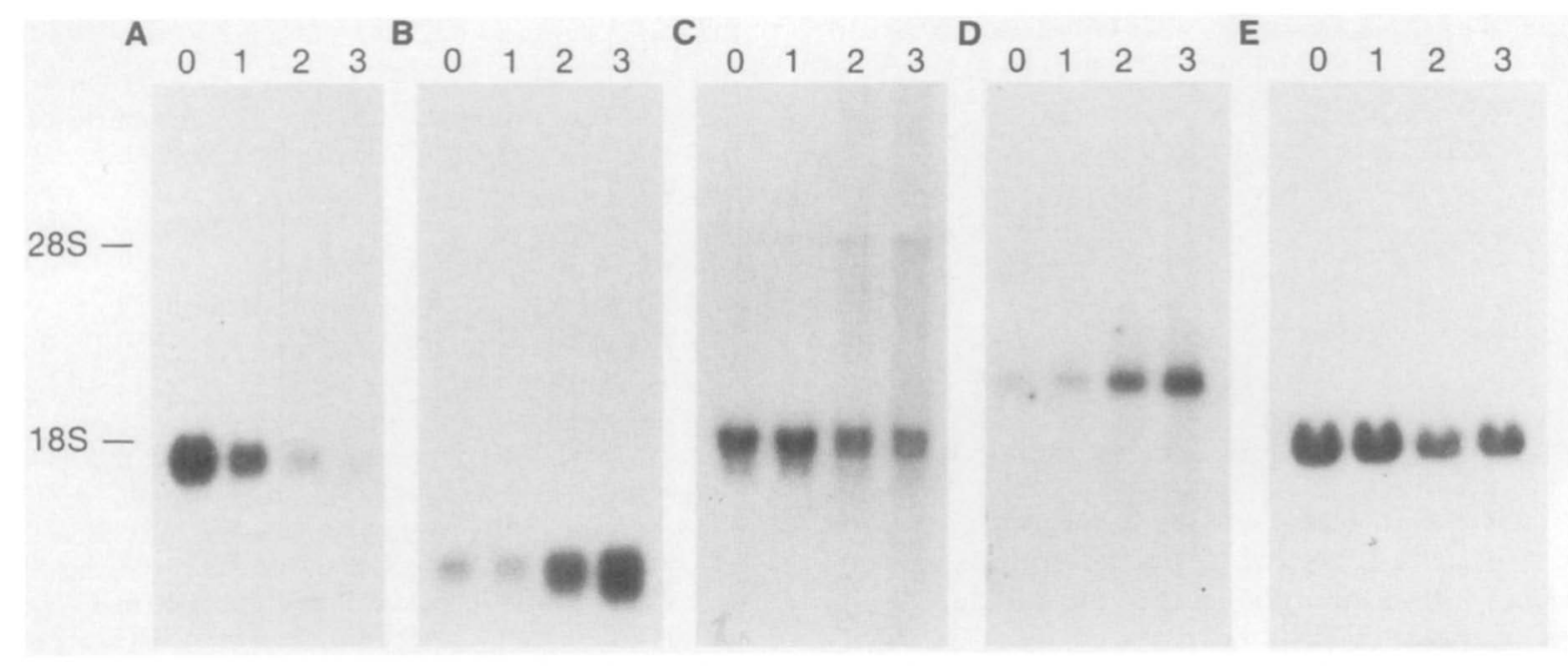

Figure 3. Northern blot analysis of total RNA from MEL cells from days $0-3$ of DMSO treatment. Total RNA from $\sim 7 \times 10^{5}$ cells from the indicated days (0-3) was loaded per lane and probed with $2 \times 10^{6} \mathrm{cpm}$ to $7 \times 10^{6} \mathrm{cpm}$ of ${ }^{32} \mathrm{P}$-labeled cDNA and exposed as follows. $(A)$ CAI $28 \mathrm{hr} ;(B)$ globin $28 \mathrm{hr}$; $(C)$ CAII $96 \mathrm{hr}$; $(D)$ ALA synthase $72 \mathrm{hr}$; $(E)$ GAPD $4 \mathrm{hr}$. Markers are 28S and 18S rRNA.

changes in steady-state levels of mRNA during induction. For CAI, globin, ALA synthase, and GAPD, changes in the transcriptional activity of the gene were accompanied by a similar increase or decrease in the steady-state level of mRNA for that gene. The exceptions were CAII and band 3 . In the case of CAII, transcriptional activity increases six- to eightfold during induction; however, CAII steady-state RNA levels decrease somewhat over the same period. We did detect a small increase in band 3 gene transcription during induction, which correlates with the appearance of the band 3 polypeptide (Sabban et al. 1980; Pfeffer and Redman 1981; Patel and Lodish 1984), but band 3 mRNA was not detectable through analysis of total MEL RNA. Band 3 gene transcription and mRNA were readily detectable in transcription assays and total RNA preparations from mouse anemic spleen (data not shown). Although comparison is difficult due to the heterogeneous and changing cell population of the anemic spleen, this result may reflect a quantitative difference in band $3 \mathrm{ex}$ pression between the MEL cell system and the mouse anemic spleen (Sabban et al. 1981).

Much is known about the transcription and kinetics of globin mRNA and polypeptide accumulation during MEL cell induction. Much less is known about the regulated expression of nonglobin gene products. ALA synthase activity has been shown to increase in MEL cells during induction with DMSO. Ebert and Ikawa (1974) and Sassa (1976) reported a steady increase in ALA synthase activity during induction. The results of Rutherford et al. (1979) indicated that ALA synthase activity increases on the first day of DMSO treatment and then decreases and levels out. Care must be taken in comparing these results since different MEL cell lines were used. Our studies show that ALA synthase gene transcription, in parallel with that of globin, increases during induction, with the most significant increase occurring between days 1 and 2 . ALA synthase steady-state
RNA levels increase accordingly. These data would support the results of Ebert and Ikawa (1974) and Sassa (1976) and suggest that ALA synthase expression is controlled primarily at the level of transcription, as is globin. However, we cannot rule out the possibility of translational or posttranslational steps in control of expression, especially in light of the results of Rutherford et al. (1979).

CAI gene transcription decreases during MEL cell induction as does the level of CAI steady-state mRNA. Stern et al. (1977) showed that when measurements are expressed as a percentage of soluble protein, CAI protein levels appear unchanged during MEL cell induction and CAII levels increase. A previous study (Sherton and Kabat 1976) demonstrated that induction of MEL cells is characterized by a $30-40 \%$ decrease in protein content per cell by day 4 . Taken together, these results suggest that the amount of CAI protein per cell decreases. Our results for CAI would support this interpretation of reduced CAI expression per cell during induction due to decreased rate of transcription and steady-state RNA level. Studies on human CAI indicate that it is a specific marker of early normal human erythroid differentiation (Villeval et al. 1985). Our results suggest that CAI may also be a marker for early erythroid differentiation in the mouse, since it is transcribed primarily in the uninduced cell and appears to be downregalated early during induction. The results for CAII are more difficult to interpret. As mentioned above, during induction CAII gene transcription increases six- to eightfold per cell, the CAII steady-state RNA level decreases slightly, whereas the percentage of CAII in soluble protein increases approximately twofold by the fourth day of DMSO treatment (Stern et al. 1977). Different posttranscriptional events could be invoked to explain these observations, e.g., changes in mRNA translatability and mRNA half-life during induction (Yenofsky et al. 1983; Krowczynska et al. 1985). However, these changes are unique to CAII ex- 
pression; they do not appear to be involved in the coordinate regulation of globin, band 3, and ALA synthase genes, which occurs primarily at the level of transcription.

GAPD and rRNA gene transcription decrease during MEL cell induction, as does the level of steady-state GAPD mRNA. Both these genes have been shown to be constitutively expressed in all tissues. The decreased expression of these genes reflects the terminally differentiating state of the MEL cells. Previous studies have shown, and our studies confirm, that induced MEL cells contain only $50-60 \%$ as much RNA as control cells (Sherton and Kabat 1976). In addition, the total transcriptional output, measured in terms of yield of nascent ${ }^{32}$ P-labeled RNA, decreases steadily during induction, approaching $50-60 \%$ of the level of the uninduced cell. Studies of erythroid cells have shown that RNA synthesis declines throughout erythropoiesis as the cells become progressively smaller and their nuclei increasingly condensed. Denton et al. (1975) have shown that the activities of glucose-6-phosphate dehydrogenase, 6-phosphogluconate dehydrogenase, adenosine deaminase, and nucleoside phosphorylase exhibit a steep decline as erythroid cells complete their final cell division. The reduced transcription for GAPD and rRNA may be part of the overall program of reduced expression of these and other genes not directly involved in the terminal stages of erythroid differentiation.

We have demonstrated that, in addition to the transcriptional activation of the $\beta$-globin gene that occurs upon induction of MEL cells, increases in the rate of transcription occur on the CAII, ALA synthase, and band 3 genes. The CAI gene is presumably activated transcriptionally at an earlier stage of erythropoiesis than is represented by the MEL cell and is downregulated upon induction. These results demonstrate the role of transcriptional regulation during erythroid differentiation and pose two questions central to understanding the molecular basis of differentiation: Is the coordinated activation of these genes determined by common cisacting and/or trans-acting factors, and is there a cascade of steps which ensures that expression of the CAI gene precedes that of globin? Our studies of the elements and factors responsible for the regulation of transcription of these genes are aimed at answering these very important questions.

\section{Methods}

\section{Recombinant plasmids}

The following plasmids containing cDNA inserts were used in this study: pMaSp, mouse $\alpha$-spectrin (pB129) (Cioe and Curtis 1985); pMEB3-18, mouse erythrocyte band 3 (Demuth et al. 1986); pMCAI, mouse carbonic anhydrase form I (Fraser and Curtis 1986); pMCAII, mouse carbonic anhydrase form II (Curtis 1983); pMBG, mouse $\beta$-major globin; pMS20, mouse ALA synthase (Schoenhaut and Curtis 1986); pGAPD, mouse glyceraldehyde phosphate dehydrogenase (unpubl.); pRG, rabies virus glycoprotein (Anilionis et al. 1981). The plasmid pABE was a gift from Dr. R.D. Schmickel and contains genomic sequences for human 28S rRNA (Erickson et al. 1981).

\section{Cells and culture conditions}

The MEL cell line C- 3 was the generous gift of Dr. D. Parker and was subcloned and maintained as previously described (Parker and Housman 1985). Cells were induced by addition of $1.8 \%$ DMSO to the culture medium.

\section{Isolation of nuclei}

Nuclei were prepared based on the method of Weintraub and Groudine (1976). Briefly, $10^{8}$ cells were pelleted and resuspended in $4 \mathrm{ml}$ of ice-cold reticulocyte standard buffer $(10 \mathrm{mM}$ Tris pH 7.5; $10 \mathrm{~mm} \mathrm{NaCl} ; 3 \mathrm{mM} \mathrm{MgCl}_{2}$ ) containing $0.1 \%$ Triton $\mathrm{mM}$ dithiothreitol, and $0.1 \mathrm{M}$ sucrose. The cells were lysed with 12 strokes of an all-glass B type dounce (Kontes) and diluted with an equal volume of the same solution containing $0.25 \mathrm{M}$ sucrose. The crude homogenate was then layered over 0.5 volumes of $0.33 \mathrm{M}$ sucrose, $5 \mathrm{mM} \mathrm{MgCl}, 10 \mathrm{mM}$ Tris $\mathrm{pH} 8.0$, $0.5 \mathrm{~mm}$ dithiothreitol, and the nuclei were pelleted at $800 \mathrm{~g}$ for 5 $\min$ at $4^{\circ} \mathrm{C}$.

\section{In vitro nuclear transcription assay}

Transcription in isolated nuclei and isolation of ${ }^{32} \mathrm{P}$-labeled nuclear RNA was performed essentially as described by Groudine et al. (1981) with the exception that $\left[{ }^{32} \mathrm{P}\right] \mathrm{UTP}$ of $3000 \mathrm{Ci} / \mathrm{mmole}$ was used. Spot blotting of plasmid DNA onto nitrocellulose was performed as follows. Five micrograms of linearized plasmid DNA was denatured for 5-10 min in $0.2 \mathrm{~N} \mathrm{NaOH}$ on ice and then neutralized with an equal volume of $1.4 \mathrm{M}$ Tris $\mathrm{pH}$ $3.5,6 \times \operatorname{SSC}(1 \times \mathrm{SSC}=0.15 \mathrm{M} \mathrm{NaCl}, 0.015 \mathrm{M} \mathrm{Na}$ citrate $)$ and spotted immediately with a Schleicher and Schuell spot blotter. After baking the spotted nitrocellulose at $80^{\circ} \mathrm{C}$ under vacuum for $2 \mathrm{hr}$, the spots were cut out with a paper punch and prehybridized for $3-5 \mathrm{hr}$ at $65^{\circ} \mathrm{C}$ in $0.3 \mathrm{ml}$ prehybridization buffer according to Hofer and Darnell (1981). Hybridizations were performed in $0.3 \mathrm{ml}$ of the same buffer for $36-48 \mathrm{hr}$ at $65^{\circ} \mathrm{C}$. The number of counts used in the hybridizations was proportional to that obtained from the nuclei from $10^{8}$ cells from days $0-3$ and ranged from $6 \times 10^{6} \mathrm{cpm}$ to $2.4 \times 10^{6} \mathrm{cpm}$, respectively. Each step of the purification procedure was monitored to insure no significant loss of labeled RNA. RNA was partially degraded by treatment with $0.2 \mathrm{~N} \mathrm{NaOH}$ for $80 \mathrm{~min}$ on ice prior to hybridization (Jelinek et al. 1974). After hybridization, the filters were rinsed three times in $0.5 \mathrm{M} \mathrm{NaCl}, 10 \mathrm{mM}$ Tris $\mathrm{pH} 7.5$ at room temperature, and single-stranded RNA was digested according to the method of Wall and Darnell (1971) in $1 \mathrm{ml}$ of the same solution containing $120 \mu \mathrm{g} / \mathrm{ml} \mathrm{RNase} \mathrm{A}$ at $37^{\circ} \mathrm{C}$ for 30 $\mathrm{min}$. Filters were then washed twice in $2 \times \mathrm{SSC}, 0.1 \%$ sodium dodecyl sulfate (SDS) for $20 \mathrm{~min}$ and once in $0.5 \times \mathrm{SSC}, 0.1 \%$ SDS for $30 \mathrm{~min}$ at $52^{\circ} \mathrm{C}$. Filters could then be counted in scintillation fluid and mounted for exposure on Kodak XAR-5 film with intensifying screens at $-70^{\circ} \mathrm{C}$.

\section{Analysis of steady-state RNA}

Total RNA was extracted from uninduced and induced MEL cells as described by Curtis and Weissmann (1976) and electrophoresed on formaldehyde-containing $1 \%$ agarose gels (Maniatis et al. 1982). RNA was then transferred to nitrocellulose, baked under vacuum for $2 \mathrm{hr}$ at $80^{\circ} \mathrm{C}$, prehybridized for $2 \mathrm{hr}$, and hybridized for $20 \mathrm{hr}$ in roller bottles at $50^{\circ} \mathrm{C}$ in $5 \times \mathrm{SSC}$, $0.08 \%$ Ficoll, $0.08 \%$ polyvinylpyrrolidone, $0.08 \% \mathrm{BSA}, 8 \mu \mathrm{g} / \mathrm{ml}$ poly(A), $100 \mu \mathrm{g} / \mathrm{ml}$ sheared and denatured salmon sperm DNA. After hybridization, the filters were washed twice in $2 \times \mathrm{SSC}$, $0.1 \%$ SDS for $20 \mathrm{~min}$ and once in $0.1 \times$ SSC, $0.1 \%$ SDS for 30 min at $65^{\circ} \mathrm{C}$ and exposed to Kodak XAR-5 film with intensifying screens at $-70^{\circ} \mathrm{C}$. 


\section{Acknowledgments}

We are grateful to Dr. R.D. Schmickel for providing the human 28S rRNA clone, and to Drs. D. Parker and D. Housman for providing the superinducible MEL cell line C3. We also thank Dr. R. Weinmann for critical reading of the manuscript. This research was supported in part by National Institutes of Health grant CA-10815. P.J.F. was supported by an N.I.H. predoctoral training grant CA-09171 to the Wistar Institute.

\section{References}

Anilionis, A., W.H. Wunner, and P.J. Curtis. 1981. Structure of the glycoprotein gene in rabies virus. Nature 294: 275-278.

Aviv, H., V. Volloch, R. Bastos, and S. Levy. 1976. Biosynthesis and stability of globin mRNA in cultured erythroleukemia Friend cells. Cell 8: 495-503.

Cioe, L. and P.J. Curtis. 1985. Detection and characterization of a mouse $\alpha$-spectrin cDNA clone by its expression in Escherichia coli. Proc. Natl. Acad. Sci. 82: 1367-1371.

Colin, Y., C. Rahuel, J. London, P.-H. Romeo, L. d'Auriol, F. Galibert, and J.-P. Cartron. 1986. Isolation of cDNA clones and complete amino acid sequence of human erythrocyte glycophorin C. I. Biol. Chem. 261: 229-233.

Cox, J.V., R.T. Moon, and E. Lazarides. 1985. Anion transporter: Highly cell-type-specific expression of distinct polypeptides and transcripts in erythroid and nonerythroid cells. I. Cell Biol. 100: 1548-1557.

Curtis, P.J. 1983. Cloning of mouse carbonic anhydrase mRNA and its induction in mouse erythroleukemic cells. $\%$. Biol. Chem. 258: 4459-4463.

Curtis, P.J. and C. Weissmann. 1976. Purification of globin messenger RNA from dimethylsulfoxide-induced Friend cells and detection of a putative globin messenger RNA precursor. J. Mol. Biol. 106: 1061-1075.

Demuth, D.R., L.C. Showe, M. Ballantine, A. Palumbo, P.J. Fraser, L. Cioe, G. Rovera, and P.J. Curtis. 1986. Cloning and structural characterization of a human non-erythroid band 3-like protein. EMBO I. 5: 1205-1214.

Denton, M.J., N. Spencer, and H.R.V. Arnstein. 1975. Biochemical and enzymic changes during erythrocyte differentiation. The significance of the final cell division. Biochem. $I$. 146: $205-211$.

Ebert, P.S. and Y. Ikawa. 1974. Induction of $\delta$-aminolevulinic acid synthetase during erythroid differentiation of cultured leukemia cells. Proc. Soc. Exp. Biol. Med. 146: 601-604.

Eisen, H., R. Bach, and R. Emery. 1977. Induction of spectrin in erythroleukemic cells transformed by Friend virus. Proc. Natl. Acad. Sci. 74: 3898-3902.

Erickson, J.M., C.L. Rushford, D.J. Dorney, G.N. Wilson, and R.D. Schmickel. 1981. Structure and variation of human ribosomal DNA: Molecular analysis of cloned fragments. Gene 16: 1-9.

Fraser, P.J. and P.J. Curtis. 1986. Molecular evolution of the carbonic anhydrase genes: Calculation of divergence time for mouse carbonic anhydrase I and II. J. Mol. Evol. 23: 294 299.

Ganguly, S. and A.I. Skoultchi. 1985. Absolute rates of globin gene transcription and mRNA formation during differentiation of cultured mouse erythroleukemia cells. I. Biol. Chem. 260: $12167-12173$.

Groudine, M., M. Peretz, and H. Weintraub. 1981. Transcriptional regulation of hemoglobin switching in chicken embryos. Mol. Cell. Biol. 1: 281-288.

Hofer, E. and J.E. Darnell. 1981. The primary transcription unit of the mouse $\beta$-major globin gene. Cell 23: 585-593.

Hofer, E., R. Hofer-Warbinek, and J.E. Darnell. 1982. Globin
RNA transcription: A possible termination site and demonstration of transcriptional control correlated with altered chromatin structure. Cell 29: 887-893.

Jelinek, W., G. Molloy, R. Fernandez-Munoz, M. Saliditt, and J.E. Darnell. 1974. Secondary structure in hnRNA: Involvement of regions from repeated RNA sites. $J$. Mol. Biol. 82: $361-370$.

Krowczynska, A., R. Yenofsky, and G. Brawerman. 1985. Regulation of messenger RNA stability in mouse erythroleukemia cells. I. Mol. Biol. 181: 231-239.

Lowenhaupt, K., C. Trent, and J.B. Lingrel. 1978. Mechanisms for accumulation of globin mRNA during dimethyl sulfoxide induction of murine erythroleukemia cells: Synthesis of precursors and mature mRNA. Dev. Biol. 63: 441-454.

Maniatis, T., E.F. Fritsch, and J. Sambrook. 1982. Molecular cloning: A laboratory manual. Cold Spring Harbor Laboratory, Cold Spring Harbor, New York.

Nudel, U., J. Salmon, E. Fibach, M. Terada, R. Rifkind, P.A. Marks, and A. Bank. 1977. Accumulation of $\alpha$ - and $\beta$-globin messenger RNAs in mouse erythroleukemia cells. Cell 12: $463-469$.

Orkin, S.H. and P.S. Swerdlow. 1977. Globin RNA synthesis in vitro by isolated erythroleukemic cell nuclei: Direct evidence for increased transcription during erythroid differentiation. Proc. Natl. Acad. Sci. 74: 2475-2479.

Parker, D. and D. Housman. 1985. Regulation of protein synthesis and accumulation during murine erythroleukemia cell differentiation. J. Biol. Chem. 260: 604-609.

Patel, V.P. and H.F. Lodish. 1984. Loss of adhesion of murine erythroleukemia cells to fibronectin during erythroid differentiation. Science 224: 996-998.

Pfeffer, S.R. and C.M. Redman. 1981. Biosynthesis of mouse erythrocyte membrane proteins by Friend erythroleukemia cells. Biochim. Biophys. Acta 641: 254-263.

Pfeffer, S.R., T. Huima, and C.V. Redman. 1986. Biosynthesis of spectrin and its assembly into the cytoskeletal system of Friend erythroleukemia cells. J. Cell Biol. 103: 103-113.

Riederer, B.M., I.S. Zagon, and S.R. Goodman. 1986. Brain spectrin (240/235) and brain spectrin (240/235E): Two distinct spectrin subtypes with different locations within mammalian neural cells. I. Cell Biol. 102: 2088-2097.

Rutherford, T., G.G. Thompson, and M.R. Moore. 1979. Heme biosynthesis in Friend erythroleukemia cells: Control by ferrochelatase. Proc. Natl. Acad. Sci. 76: 833-836.

Sabban, E.L., D.D. Sabatini, V.T. Marchesi, and M. Adesnik. 1980. Biosynthesis of erythrocyte membrane protein band 3 in DMSO-induced Friend erythroleukemia cells. I. Cell. Physiol. 104: 261-268.

Sabban, E., V. Marchesi, M. Adesnik, and D.D. Sabatini. 1981. Erythrocyte membrane protein band 3: Its biosynthesis and incorporation into membranes. J. Cell Biol. 91: 637-646.

Sassa, S. 1976. Sequential induction of heme pathway enzymes during erythroid differentiation of mouse Friend leukemia virus-infected cells. I. Exp. Med. 143: 305-315.

Schoenhaut, D.S. and P.J. Curtis. 1986. Nucleotide sequence of mouse 5-aminolevulinic acid synthase cDNA and expression of its gene in hepatic and erythroid tissues. Gene 48: $55-63$.

Sherton, C.C. and D. Kabat. 1976. Changes in RNA and protein metabolism preceding onset of hemoglobin synthesis in cultured Friend leukemia cells. Dev. Biol. 48: 118-131.

Stern, R.H., S.H. Boyer, J.-F. Conscience, C. Friend, L. Margolet, R.E. Tashian, and F.H. Ruddle. 1977. Carbonic anhydrase isozymes in cultured Friend leukemia cells. Proc. Soc. Exp. Biol. Med. 156: 52-55.

Tashian, R.E. 1977. Evolution and regulation of the carbonic anhydrase isozymes. In Isozymes: Current topics in biolog- 
ical and medical research (ed. M.C. Rattazzi et al.), vol. 2, pp. 21-62. Alan R. Liss, Inc., New York.

Villeval, J.L., U. Testa, G. Vinci, H. Tonthat, A. Bettaieb, M. Titeux, P. Cramer, L. Edelman, H. Rochant, J. BretonGorius, and W.W. Vainchenker. 1985. Carbonic anhydrase I is an early specific marker of normal human erythroid differentiation. Blood 66: 1162-1170.

Volloch, V. and D. Housman. 1982. Terminal differentiation of murine erythroleukemia cells: Physical stabilization of endstage cells. J. Cell Biol. 93: 390-394.

Wall, R. and J.E. Darnell. 1971. Presence of cell and virus-specific sequences in the same molecules of nuclear RNA from virus transformed cells. Nature New Biol. 232: 73-76.

Weintraub, H. and M. Groudine. 1976. Chromosomal subunits in active genes have an altered conformation. Science 93: $848-853$.

Yenofsky, R., S. Cereghini, A. Krowczynska, and G. Brawerman. 1983. Regulation of mRNA utilization in mouse erythroleukemia cells induced to differentiate by exposure to dimethyl sulfoxide. Mol. Cell. Biol. 3: 1197-1203. 


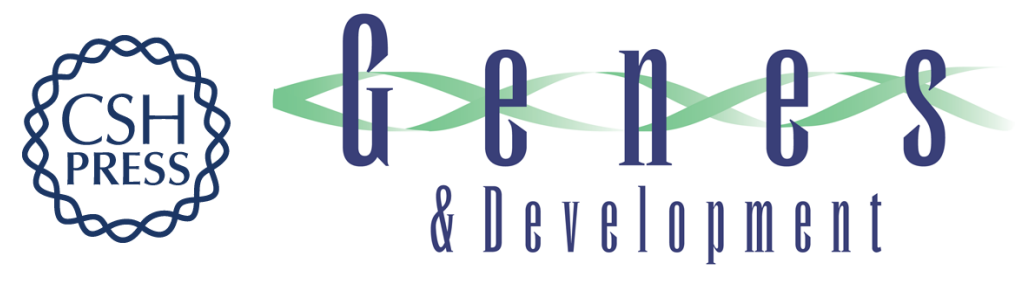

\title{
Specific pattern of gene expression during induction of mouse erythroleukemia cells.
}

\author{
$\mathrm{P}$ J Fraser and P J Curtis
}

Genes Dev. 1987, 1:

Access the most recent version at doi:10.1101/gad.1.8.855

\section{References This article cites 39 articles, 19 of which can be accessed free at: http://genesdev.cshlp.org/content/1/8/855.full.html\#ref-list-1}

\section{License}

Email Alerting

Receive free email alerts when new articles cite this article - sign up in the box at the top Service right corner of the article or click here.

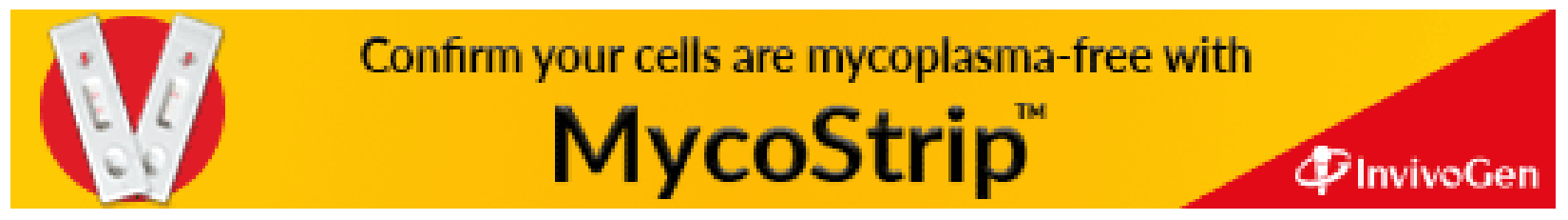

